\title{
Altering Trends in the Epidemiology of Type 1 Diabetes Mellitus in Children and Adolescents
}

\author{
Elisavet Efstathiou and Nicos Skordis \\ Paediatric Endocrine Unit, Department of Paediatrics, \\ Makarios Hospital, Nicosia \\ Cyprus
}

\section{Introduction}

Diabetes mellitus is a group of metabolic diseases characterised by chronic hyperglycemia resulting from defects in insulin secretion and/or insulin action, or both [1]. The history of diabetes dates back to $1550 \mathrm{BC}$ as the polyuric states were described in an Egyptian papyrus, where treatment was given with a four day decoction of bones, wheat, grain, grit and earth. The term diabetes was coined by Aretaeus of Cappadocia in the $2^{\text {nd }}$ century AD for conditions causing increased urine output. The sweet taste of diabetic urine was noted in the $5^{\text {th }}$ century AD by Indian physicians and in 1776, Matthew Dobson confirmed that diabetic serum and urine contained sugar. The revolution in the history of Diabetes was the discovery of insulin by Banting, Best and colleagues in 1922 (http://wwunix.oit.umass.edu / abhu000/diabetes/index.html).

Type 1 diabetes mellitus (T1DM) is one of the most common endocrine metabolic disorders in children and adolescence worldwide with serious acute and chronic complications. It has been proven that T1DM represents the ending result of an autoimmune destruction of the pancreatic islet beta cells in genetically susceptible individuals exposed to certain but still unclear environmental factors. The precise cause of T1DM is not known. However, multiple genetic and environmental risk factors seem to play an important role in the genesis of the disease. The genetic background is complex and difficult to be explained by the involvement of HLA gene region alone. On the other hand viral and nutritional factors changing continuously from country to country, may contribute to the etiology of T1DM. There is no doubt that monitoring temporal trends and incidence of T1DM contribute to the international effort to determine the exact pathogenesis of the disease and it is of critical public health importance. All these temporal trends in the incidence of T1DM have provided significant clues for understanding the disease, most likely reflecting environmental changes more than genetic changes and detecting the factors that implicated in this increase.

In this chapter we review the changing trends in the epidemiology of T1DM and we present data on the rising incidence of T1DM in Greek Cypriot population.

\section{Incidence-changing trends}

The prevalence of T1DM greatly varies between different countries, within countries, and between different ethnic populations. The global variation of the incidence of T1DM is 
evaluated by grouping the populations with very low $(<1 / 100.000$ per yr), low $(1-4 / 100.000$ per yr), intermediate (5-9.99/100.000 per yr), high (10-19.99/100.000 per yr) and very high (>20/100.000 per yr) incidence [2]. The different annual incidence rates of T1DM comparing different countries of the world ( 0.1 to 57.6 per 100000) are displayed in figure 1 [1]. The highest incidence is observed in the Scandinavian countries, where Finland has the highest one reported while there is a gradual decrease in countries located closer to equator [3]. However in some areas such as Puerto Rico, Kuwait and Sardinia there is an unexplained highly increased incidence [4]. The lowest incidence in the world is observed in China, where an enormous geographic variation in the development risk is observed [5]. A long time ago, during the 5th century BC, Hippocrates described diabetes as a 'rare condition' while later on Arataeus the Cappadocian described it as 'not being frequent among men' (http://wwunix.oit.umass.edu/ abhu000/diabetes/index.html). Nowadays the incidence of T1DM increases dramatically throughout the world and it is estimated that it may reach the status of an epidemic in the $21^{\text {st }}$ century [6].

A number of 37 studies from 27 countries confirmed the increased incidence for the period 1960-96 in T1DM with an upward tendency in another 12 countries. The global average annual increase was $3.0 \%$ per year with a more pronounced relative increase in the populations with lower incidence [7]. If these trends continue, the number of new cases T1DM in children younger than five years of age may double in some regions between 2005 and 2020 and prevalent cases in children under 15 years will rise by $70 \%$ [8].

The need for rigorous epidemiological studies to monitor the trends of T1DM in children less than 15 year of age led to the creation of the World Health Organization ( WHO) sponsored Diabetes Mondiale (DIAMOND) [2] Project and the EURODIAB study [9].

The data from the WHO project for the incidence of T1DM worldwide DIAMOND showed a large geographic variability. This study group was based on 43,013 cases of T1DM from a study population of 84 million children aged 14 year old or less during the period 1990-1999 in 114 populations from 57 countries. During this time the average annual increase in incidence was 2.8\% (95\% CI 2.4\%-3.2\%) with a slightly higher rate during 1995 to $1999,3.4 \%$ (95\% CI 2.7\%-4.3\%) than during 1990 to 1994, 2.4\% (95\% CI 1.3\%-3.4\%). An increase in the incidence of T1DM was observed in the populations studied (4.0\% in Asia, 3.2\% in Europe, and $5.3 \%$ in North America) with the exception of Central America and the West Indies, where T1D is less prevalent, and where the trend was a decrease of 3.6\% [10].

It is of interest that several reports have shown an increase in the incidence of T1DM worldwide. This tendency implicates an increasing influence of environmental trigger factors against a background of genetic susceptibility. The geographic and ethnic variations mirror the prevalence of susceptibility genes or that of contributing environmental factors, or both. Nevertheless this increasing incidence rate in such a short period cannot be solely attributed to genetic shifts.

The EURODIAB ACE study group examined the trends in the incidence of T1DM from 1989 to 1994. The study was based on 16,362 cases of T1D in 44 European centres and Israel covering a population of 28 million children [9]. There were enormous variations in the annual incidence rate with 3.2/100,000 person-years in the Former Yugoslav Republic of Macedonia to $40.2 / 100,000$ person-years in two regions of Finland. During this time the annual increase in the incidence rate of T1D was 3.4\% (95\% CI 2.5\%-4.4\%) although the rate of increase was noted to be higher in some central European countries. The rates of increase were found to be the highest in the youngest age group: ages 0 to 4 years $(6.3 \%, 95 \%$ CI $1.5 \%-8.5 \%), 5$ to 9 years $(3.1 \%, 95 \%$ CI $1.5 \%-4.8 \%)$, and 10 to 14 years $(2.4 \%, 95 \%$ CI $1.0 \%-3.8 \%)$. 


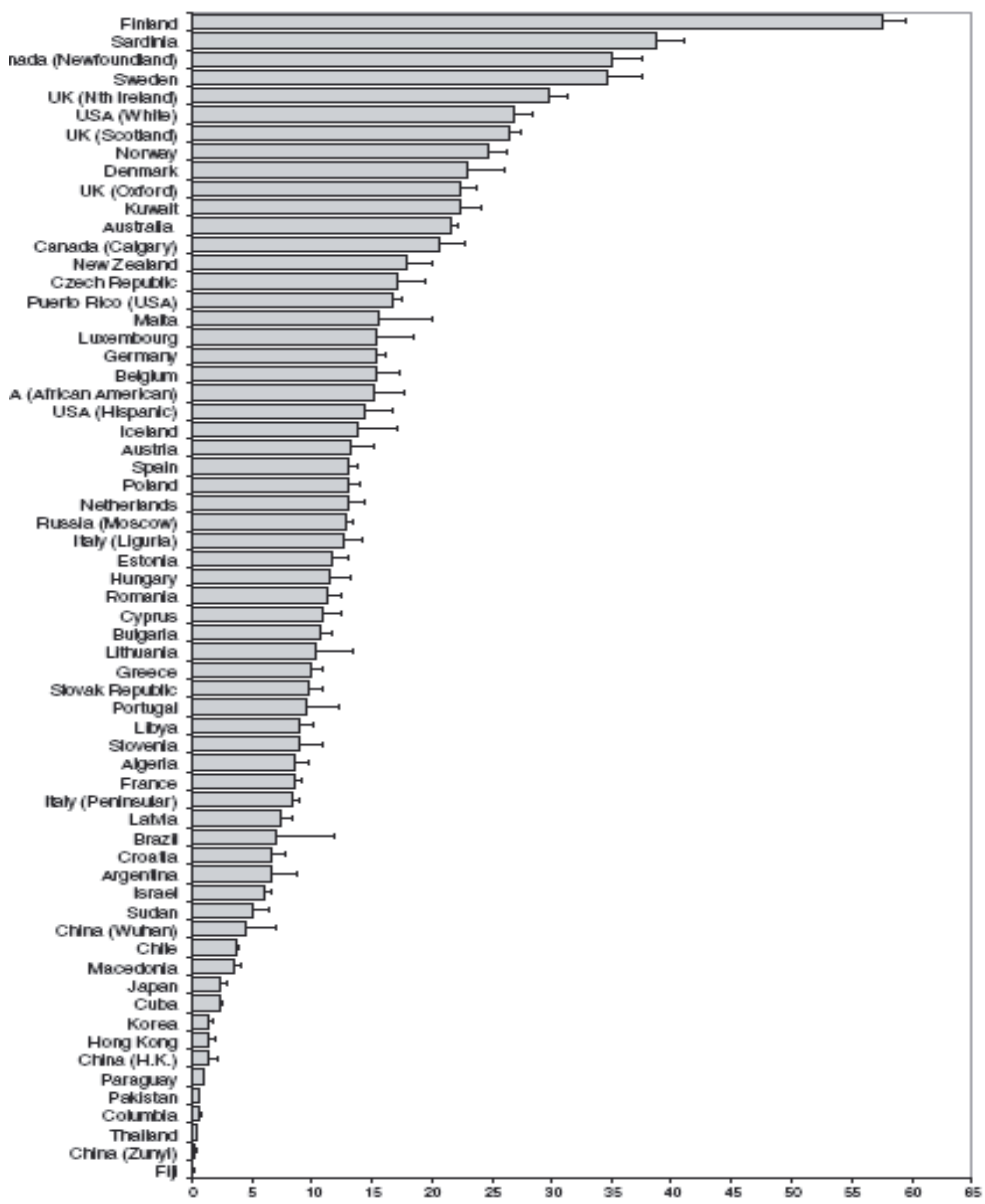

Fig. 1. Mean Annual Incidence rates for T1DM comparing different countries in the world as seen in reference 1.

Furthermore one of the most notable and recent, in the United States, includes a populationbased study of incidence rates of T1DM from 10 study locations by The SEARCH for Diabetes in Youth Study. The Search Group found an overall incidence of T1DM in children 0-19 of 24.3 per 100,000 person years with the highest rates observed among the 5-9 and 1014 age groups with rates of 22.9 and 33.9 per 100,000 respectively [11].

A recent study from Saudi Arabia over an 18 year period, has shown an average incidence of 27.52/100000/year increasing from 18.05/100000/year in the first 9 years of the study period to 36.99/100000/year in the next 9 years [12]. Significant increase in incidence of T1DM was also observed in Lower Silesia during the period 2000-2005 with an increase from 10.43/100000 in 2000 to 13.49/100000 in 2005 [13].

Additionally in Scotland two studies by Patterson and co-workers [14-15] have shown an increasing incidence from 13, 8/100000/year between 1968 and 1976 and up to 
21,0/100000/year from 1977 to 1983 for children aged less than 19 year old. Another study for the same population found that the incidence of T1DM had increased from 22,7/100000 in 1984 to 26,0/100000 in 1993 and this increase of about 2\% a year, though small, is statistically significant and the effect over 10 years is a large increase [16]. An important increase in incidence of T1DM was also observed in Saxony between the five year periods 1999-2003 and 2004-2008 with estimated rates 15.7/100000 and 19.2/100000 respectively [17].

In our study we have ascertained the mean annual incidence on T1DM in the Greek Cypriot population during the period 1990 - 1999 in children younger than 15 years of age. During this period the incidence of T1DM was 10.76 /100000[18]. In order to identify an increase in the incidence of T1DM in our country, as occurred in the majority of the populations worldwide, we had performed an analysis of the newly diagnosed cases until the end of the year 2004. There was a statistically significant increase in the incidence during the period 2000-2004 with an estimated mean overall incidence 11.9/100000[19]. We had subsequently extended this work by adding the new cases of the five year period 2005 - 2009 in order to document this rising trend by comparing the incidence between the two decades (1990-1999 vs 2000-2009). We have observed a rising trend of the mean incidence from 10.76/100.000 at the first decade (1990-1999) of the study up to 14.4/100.000 at the second decade (2000-2009). According to Wilcoxon two-sample test this increasing trend of incidence during the 20 years analysed is statistically significant ( $p$-value $=0.0091)$. The mean incidence rate for each 5 year- period in accordance with the population data (population below the age of 15yr) is presented in figure 2. The overall mean incidence of T1DM, in the Greek Cypriot population was 12.46/100000 during the twenty-year period 1990-2009. This raised incidence classifies Cyprus among the countries with high incidence of T1DM.

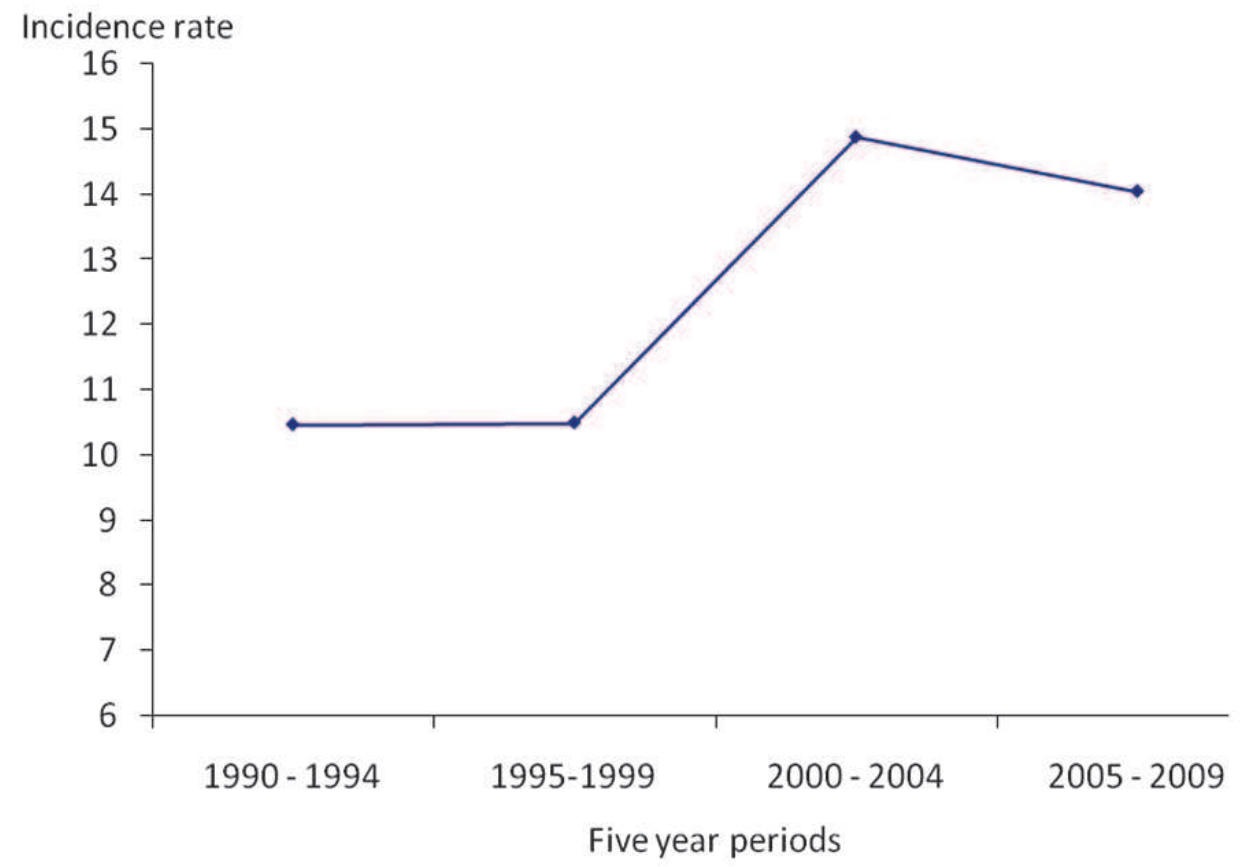

Fig. 2. Different annual incidence rates during five year periods. 
Additionally this rising incidence was more pronounced among children who manifested the disease before the age of 5yr. Table 1 shows the percentage of newly diagnosed T1DM cases expressed as age group in accordance with the international standards.

\begin{tabular}{|c|c|c|c|c|c|c|}
\hline \multirow{3}{*}{$\begin{array}{l}\text { Period at } \\
\text { Diagnosis }\end{array}$} & \multicolumn{6}{|c|}{ Age Group (years) } \\
\hline & \multicolumn{2}{|r|}{$0-4$} & \multicolumn{2}{|r|}{$5-9$} & \multicolumn{2}{|r|}{$10-14$} \\
\hline & $\mathbf{n}$ & $\%$ & $\mathbf{n}$ & $\%$ & $\mathbf{n}$ & $\%$ \\
\hline 1990-1999 & 31 & $19.0(13.0-25.0)$ & 66 & $40.5(33.0-48.0)^{* *}$ & 66 & $40.5(33.0-48.0)^{* *}$ \\
\hline 2000-2009 & 55 & $26.4(20.4-32.4)$ & 77 & $37.0(30.4-43.6)^{*}$ & 76 & $36.5(30.0-43.0)^{*}$ \\
\hline 1990-2009 & 86 & $23.2(18.9-27.5)$ & 143 & $38.5(33.5-43.5)^{* *}$ & 142 & $38.3(33.4-43.2)^{* *}$ \\
\hline
\end{tabular}

Table 1. Age of diagnosis in total and in the three age groups. Binomial test performed to compare proportions compared to “0-4 year" age group: ${ }^{*} \mathrm{p}<0.01,{ }^{* *} \mathrm{p}<0.001$

\section{Age of onset}

T1DM formerly called as juvenile diabetes it is one of the most common chronic disease of youth as $80 \%$ of individuals with T1DM are younger than 20 year of age [20-21]. The age of manifestation of childhood onset T1DM has a bimodal allotment with one peak at 4 to 6 years of age and a second in early puberty (10 to 14 years of age) [22-23]. Recent studies report a higher rate of increase among children younger than 5 years than in children between 5 and 15 years of age [24-25]. This may be related to an earlier onset of clinical manifestation or to a true increase in the causative factors of the disease.

Although the clinical appearance occurs at all ages [21] one fourth of individuals with T1DM are diagnosed as adults [26]. Up to $10 \%$ of adults primarily supposed to have type 2 diabetes are found to have antibodies associated with T1D [27] and beta cell destruction in adults seems to take place at a much slower rate than in young T1D cases, often delaying the need for insulin therapy after diagnosis.

\section{Gender differences}

Although most autoimmune diseases are more common in females, there appears to be no gender difference in the overall incidence of childhood T1DM [11].

However, a gender influence on the age of onset has been reported, in select populations. Some data reported from Europe suggest a female predominance in lower risk populations, and slight male excess in the high risk groups [3]. Furthermore many reports showed that older male adults of European origin ( $\geq 15$ to 40 years of age) are more likely to develop T1DM than females of similar age and geographic location with an approximate 3:2 male to female ratio [28-30]. The same 3:2 male to female ratio also was reported in children younger than 6 years of age in an observational study from Boston [31]. Based on our data it seems that more males develop T1DM at younger age, whereas female predominate during the peripubertal period as shown in figure 3 .

\section{Seasonal variation at onset and birth}

The first report of seasonal variation in the manifestation of T1DM was presented by Franklin Adams in 1926[32] although a consistent picture on the real seasonality of the disease has not been established. The increased incidence of T1DM diagnosis during 


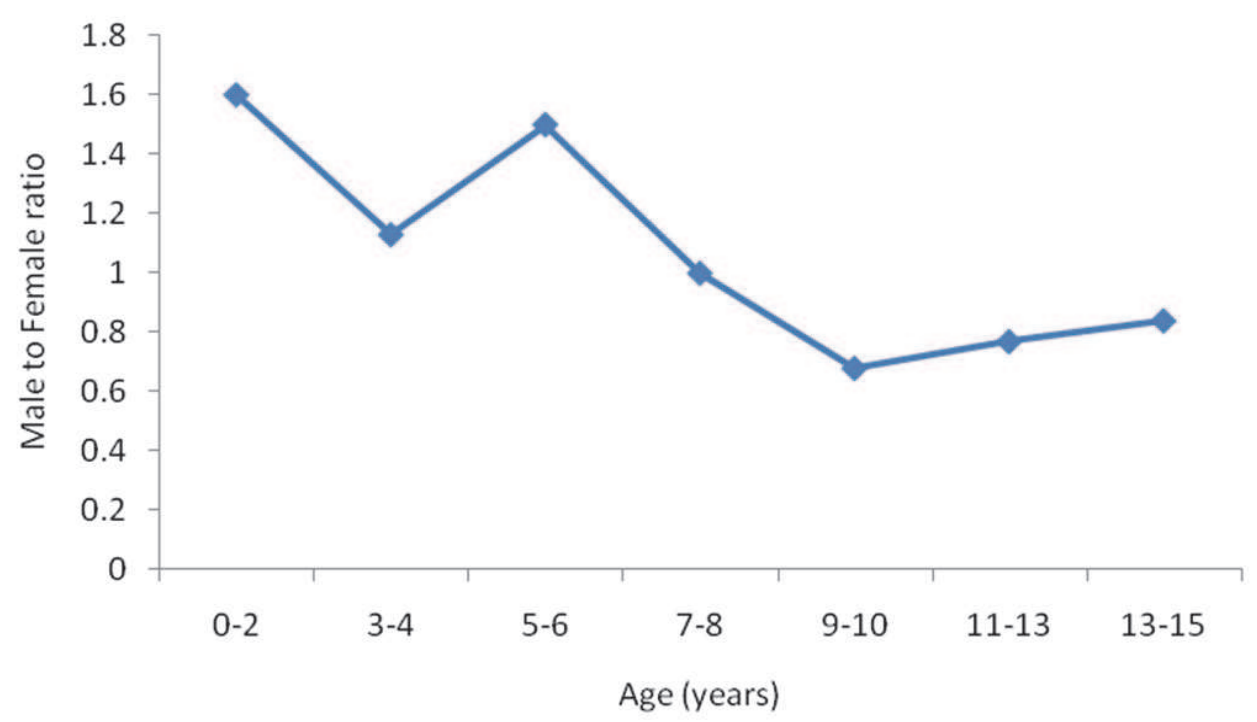

Fig. 3. Ratio of males and females in relation to year of diagnosis (at 2-yr intervals).

Autumn and Winter months could support the hypothesis that infections may act as participating factors in the clinical onset of the disease, possibly accelerating an autoimmune process that may have been initiated months or years before [33]. Based on the average temperature record in our island, the newly diagnosed cased were grouped according to the month of diagnosis as follow: November, December, January, and February were defined as cold months, October, March, April and May as neutral months and, June, July , August and September, as warm months. More children were significantly diagnosed with T1DM during the cold months compared to those who manifested the disease during the warm months $(\mathrm{p}<0.001)$, whereas no difference was observed in the incidence between neutral and cold months ((p>0.05) throughout the study period (1990-2009) as depicted in Table 2. A recent study on seasonal variation in DM in 53 countries has suggested that seasonality in the diagnosis of T1DM occurs and that the pattern of seasonality appears to be related to the geographical position, at least as far as the northern/southern hemisphere dichotomy is concerned [34].

\begin{tabular}{|c|c|c|c|c|c|c|}
\hline \multirow{3}{*}{$\begin{array}{l}\text { Period at } \\
\text { Diagnosis }\end{array}$} & \multirow{2}{*}{\multicolumn{2}{|c|}{ Cold Months }} & \multicolumn{2}{|c|}{ Month at Diagnosis } & \multirow{2}{*}{\multicolumn{2}{|c|}{ Warm Months }} \\
\hline & & & & utral Months & & \\
\hline & $\mathbf{n}$ & $\%$ & $\mathbf{n}$ & $\%$ & $\mathbf{n}$ & $\%$ \\
\hline 1990-1999 & 64 & $38.6(31.2-46.0)$ & 61 & $36.7(29.4-44.0)^{*}$ & 41 & $\begin{array}{c}24.7(18.1- \\
31.3)^{\star * * *}\end{array}$ \\
\hline $2000-2009$ & 82 & $39.4(32.8-46.0)$ & 67 & $32.2(25.9-38.5)^{* *}$ & 59 & $28.4(22.3-34.5)^{\star \star *}$ \\
\hline 1990-2009 & 146 & $39.0(34.1-43.9)$ & 128 & $34.2(29.4-39.0)^{*}$ & 100 & $\begin{array}{c}26.7(22.2- \\
31.2)^{* * * * *}\end{array}$ \\
\hline
\end{tabular}

Table 2. Percentage of children diagnosed with T1DM at cold months, neutral months and warm months. Binomial test performed to compare proportions compared to "Cold Months" group: * NS ( $p>0.05),{ }^{* *} \mathrm{p}<0.05,{ }^{* * *} \mathrm{p}<0.01,{ }^{* * * *} \mathrm{p}<0.001$ 
A seasonal variation of birth has been also observed in children who developed T1DM later in life in many countries, which suggests that environmental factors during pregnancy, in the neonatal period or very early in life play a role in its development. Several studies from Europe [35-37] and Israel [38] showed higher rates of T1DM among youth born in spring and lower rates among youth born in winter. Although McKinney maintained that there is no relationship between T1DM diagnosis and date of birth[39]. It has been suggested that seasonability pattern may be explained by reduced vitamin D production [40] during the critical intrauterine and neonatal periods of life.

\section{Genotype}

The genetics of T1DM cannot be classified according to a specific model of inheritance. Susceptibility to autoimmune T1DM is determined by multiple genes with HLA genes having the strongest known association. HLA antigens are present on the surface of the leucocytes and participate in some immune reactions. The genes coding for these antigens are located on chromosome 6 . The class II sub region of HLA consists of the DR, DQ, and DP loci. These class II molecules are involved to the immune destruction of the pancreatic beta cells because they participate in the presentation of the antigen to the helper $\mathrm{T}$ cell, which initiates the immune reaction.

Inheritance of HLA-DR3 and HLA-DR4 appears to confer a 2 to 3 fold increased risk for the development of T1DM. When both HLA-DR3 and HLA-DR4 are inherited the relative risk for the development of T1DM is increased by 7-10 folds. It is estimated that 48 percent of the familial aggregation can now be ascribed to known loci, and the Major Histocompatibility Complex (MHC) contributes 41 percent [41]. As an example, siblings with the highest risk HLA DR and DQ alleles, who inherit both HLA regions identical by descent to their diabetic sibling, may have a risk of developing anti-islet autoimmunity as high as 80 percent and a similar long-term risk of diabetes[42]. Moreover HLA DR2 and HLA DR5 are both protective in most studies. Furthermore, stronger associations of DM1 have been reported with other MHC loci: HLA-DQA1 and DQB1 antigens[43].

In our effort to detect the genetic susceptibility of Greek Cypriot population to DM1, we studied 101 DM1 patients with age of onset less than 15 years through HLA serological typing for the DR and DQ1 alleles and compared them to 209 healthy controls. Our findings support the strong association of HLA-DR4 and DR3 with DM1. The most frequent allelic combination was that of HLA-DR3/DR4 (27\%) followed by that of DR2/DR4 (21.6\%). The percentage of HLA antigens in patients with DM1 and controls are shown in figure 4 . The protective role of HLA-DR5 was shown, whereas the presence of HLA-DR2 is neutral, in contrast with most findings among Caucasian population where DR2 is protective. In addition, high resolution testing of the DR4 and DR3 alleles revealed the predominant presence of the DRB1*0403 (0\% vs 36\%), similar frequency of the DRB1*0402 in both groups (19\% vs $14 \%)$ and that the DRB1*301 was the only DR3 allele detected. The DQB1 alleles present in our T1DM patients as shown in figure 5 were nearly exclusively DQB1*0201 and DQB1*0302 [44]. The relative risk of developing T1DM in children carrying the DQB1*0201 and the DQB1*0302 alleles is 5.05 and 2.56 respectively whereas the protective role of DQB1*0301 is documented.

Furthermore, although most T1D cases occur in individuals without a family history of the disease, T1D is strongly influenced by genetic factors. The lifelong risk of T1DM is markedly 


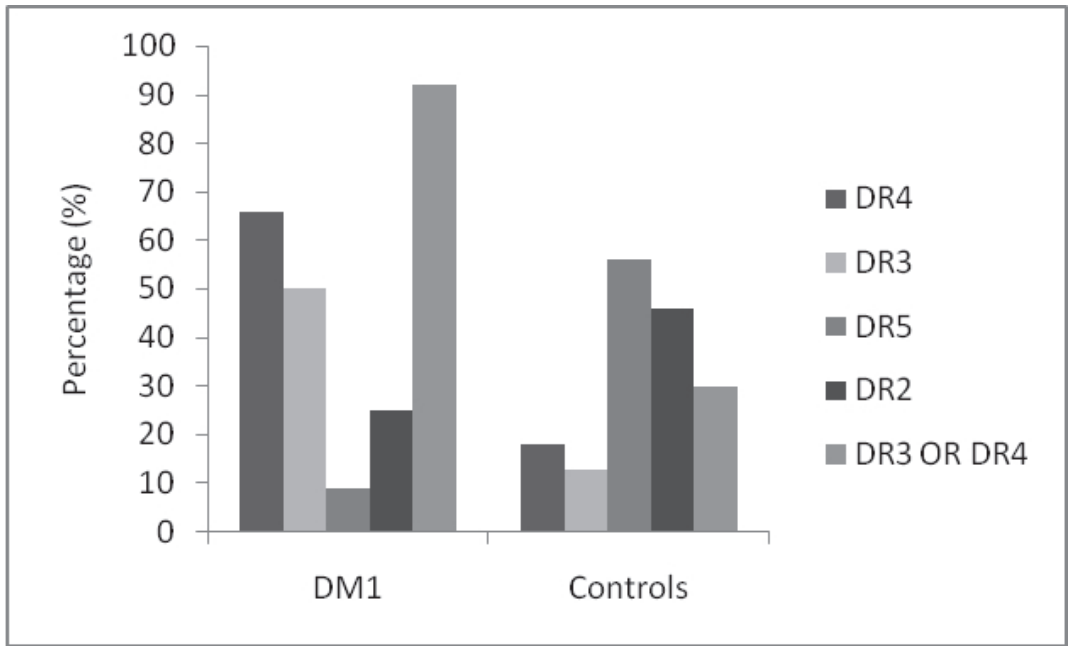

Fig. 4. HLA antigens in DM1 patients and controls.

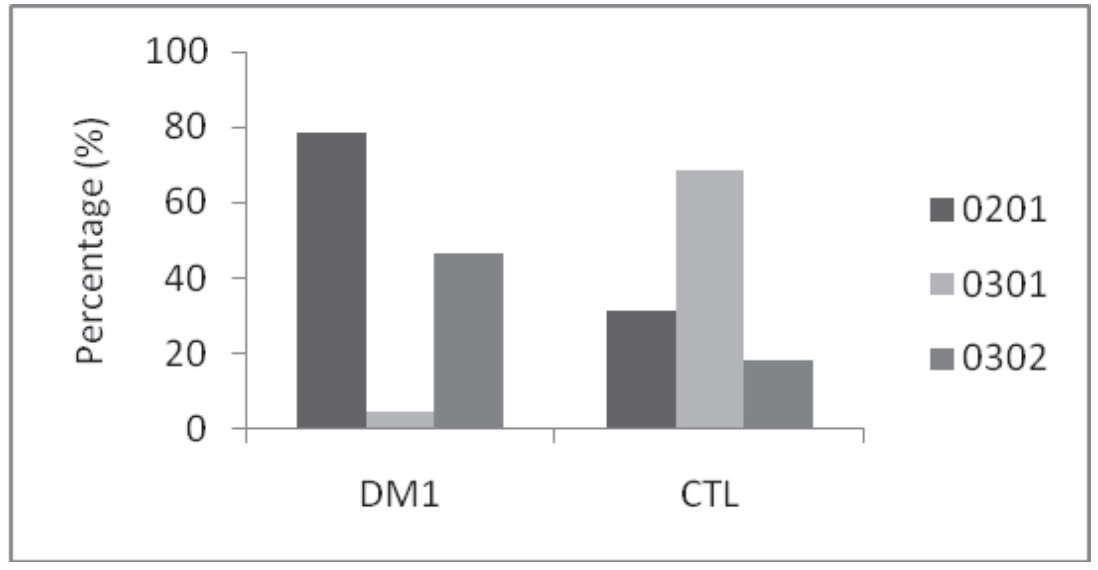

Fig. 5. HLA DQ B1 alleles in DM1 patients and controls.

increased in close relatives of a patient with T1DM, averaging about 6 percent in offspring, 5 percent in siblings and 50 percent in identical twins (versus 0.4 percent in subjects with no family history) [45-46]. T1DM is 2-3 times more common in the offspring of diabetic men (3.6-8.5\%) compared with diabetic woman (1.3-3.6\%) [1]. A monozygotic twin of a patient with type 1 diabetes has a higher risk of diabetes than a dizygotic twin, and the risk in a dizygotic twin sibling is similar to that in non-twin siblings [46].

Additionally age at onset is inversely related to the proportion of HLA haplotypes, and young children with T1DM show the greatest HLA-associated genetic risk. Siblings of children with onset of T1D before the age of 5 years have a 3- to 5-fold greater cumulative risk of diabetes by age 20 years compared with siblings of children diagnosed between 5 and 15 years of age [47]. Several reports suggest a higher proportion of lower risk haplotypes 
and in association with the decreased age at onset of T1DM are consisted with a major environmental effect on the development of the disease [48-51].

T1DM is associated with other autoimmune diseases such as thyroiditis, celiac disease, autoimmune gastritis and Addison disease [52]. The coexistence of these autoimmune diseases is associated to genes within the MHC complex [52].

\section{Other risk factors}

The variations in the incidence of T1DM in different countries its rising in rich and developed countries have raised questions about changes in environmental risk factors that may either initiate or accelerate the autoimmune process leading to pancreatic $\beta$-pancreatic cell destruction.

Reports have linked several environmental factors to an increased risk of T1DM; however, none of these have associations have verified and many have been contradicted by other studies. They include: viral infections in infancy and early childhood, maternal viral infection during pregnancy [53], early exposure to cow's milk and other nutritional factors [54], chemical contamination of food and water [55], high birth weight and an increase in body mass index [56].

Viruses that have been associated with T1DM as environmental triggers include enteroviruses, mumps, rubella, cytomegalovirus, rotavirus and Epstein-Barr virus. The one proven environmental virus trigger T1DM is congenital rubella [57]. Many epidemiological studies have been supported the involvement of enteroviruses, especially the Coxsackie B viruses in the aetiology which appears to trigger $\beta$ cell autoimmunity [58-59]. Furthermore it has been hypothesized that excessive weight gain and increase in insulin resistance in early childhood is trigger event which initiates the autoimmunity leading to $\beta$ cell destruction and this Accelerator Hypothesis has been supported by several epidemiological studies [56, 60-61].

A number of dietary factors may influence the development of T1DM in infants at high risk for T1DM. Early introduction to the infant diet of cattle proteins, lack or short lasting breast feeding might be reasons for development of immunological reaction leading to the destruction of pancreatic beta cells [62]. In two large prospective cohort studies of newborns at high risk for T1DM diabetes (either a first degree relative [63-64] or a high risk HLA genotype) [63], first exposure to cereal before age three months [63-64] or after seven months [63] was associated with an increased risk of developing autoantibodies (IA) compared to infants whose first exposure was between ages four to six months. The increased risk was associated with gluten-containing cereals in one study [64], but with either gluten or rice-containing cereals in the other [63].

On the other hand Vitamin D and omega-3 fatty acids may have a protective role. A case control study in seven European countries suggested that supplementation with vitamin D in early infancy can protect against development of T1DM [65]. A similar protective effect was found in a birth-cohort study of over 10,000 children [66]. Moreover preliminary studies in animals sustain a protective role of omega- 3 fatty acids in the inflammatory reaction associated with autoimmune islet cell damage [67-68].

In conclusion there is no doubt that the incidence of T1DM is increasing dramatically. Data from large epidemiological studies worldwide indicate that the incidence of T1DM has been increasing by $2 \%$ to $5 \%$ worldwide [69] and this is of concern because of its health and resource implications. This rising incidence of T1DM in young children has been confirmed 
to a genetically susceptible subgroup of the population (48). The heightened proportion of lower risk hapltotypes and decreased median age at onset of T1DM within the subgroup are consistent with a major environmental effect on Diabetes development (50).

\section{Epilogue}

It is a an actuality that significant advances have been made in the clinical care of T1DM, which ultimately improved the clinical outcomes. However much more need to be done to find a cure for T1DM. In the absence of an ideal therapy Diabetes will always be a hurdle in the quality of life of these children. Moreover the increasing incidence is of concern because of its health and resource implications. There is a great research potential and more studies are required to identify the environmental factors that trigger the autoimmune destruction of the pancreatic beta cell particularly in some populations and individuals, who are not genetically predisposed to develop T1DM. These environmental triggers if ever identified could potentially be targeted for new preventive strategies and optimal intervention.

\section{References}

[1] Craig, M.E., A. Hattersley, and K.C. Donaghue, Definition, epidemiology and classification of diabetes in children and adolescents. Pediatr Diabetes, 2009. 10 Suppl 12: p. 3-12.

[2] Karvonen, M., et al., Incidence of childhood type 1 diabetes worldwide. Diabetes Mondiale (DiaMond) Project Group. Diabetes Care, 2000. 23(10): p. 1516-26.

[3] Green, A., E.A. Gale, and C.C. Patterson, Incidence of childhood-onset insulin-dependent diabetes mellitus: the EURODIAB ACE Study. Lancet, 1992. 339(8798): p. 905-9.

[4] Eisenbarth, G.S., Immunology of type 1 diabetes. 2nd ed. 2004: Plenum Publishers.

[5] Yang, Z., et al., Childhood diabetes in China. Enormous variation by place and ethnic group. Diabetes Care, 1998. 21(4): p. 525-9.

[6] Silink, M., Childhood diabetes: a global perspective. Horm Res, 2002. 57 Suppl 1: p. 1-5.

[7] Onkamo, P., et al., Worldwide increase in incidence of Type I diabetes--the analysis of the data on published incidence trends. Diabetologia, 1999. 42(12): p. 1395-403.

[8] Patterson, C.C., et al., Incidence trends for childhood type 1 diabetes in Europe during 19892003 and predicted new cases 2005-20: a multicentre prospective registration study. Lancet, 2009. 373(9680): p. 2027-33.

[9] Variation and trends in incidence of childhood diabetes in Europe. EURODIAB ACE Study Group. Lancet, 2000. 355(9207): p. 873-6.

[10] Incidence and trends of childhood Type 1 diabetes worldwide 1990-1999. Diabet Med, 2006. 23(8): p. 857-66.

[11] Dabelea, D., et al., Incidence of diabetes in youth in the United States. JAMA, 2007. 297(24): p. 2716-24.

[12] Al-Mendalawi, M.D., et al., Incidence trends of childhood type 1 diabetes in eastern Saudi Arabia. Saudi Med J, 2010. 31(9): p. 1074-5; author reply 1074-5.

[13] Zubkiewicz-Kucharska, A. and A. Noczynska, [Epidemiology of type 1 diabetes in Lower Silesia in the years 2000-2005]. Pediatr Endocrinol Diabetes Metab, 2010. 16(1): p. 45-9. 
[14] Patterson, C.C., et al., Increasing prevalence of diabetes mellitus in children. Br Med J (Clin Res Ed), 1983. 287(6386): p. 213-4.

[15] Patterson, C.C., et al., Geographical variation in the incidence of diabetes mellitus in Scottish children during the period 1977-1983. Diabet Med, 1988. 5(2): p. 160-5.

[16] Rangasami, J.J., et al., Rising incidence of type 1 diabetes in Scottish children, 1984-93. The Scottish Study Group for the Care of Young Diabetics. Arch Dis Child, 1997. 77(3): p. 210-3.

[17] Galler, A., et al., Incidence of childhood diabetes in children aged less than 15 years and its clinical and metabolic characteristics at the time of diagnosis: data from the Childhood Diabetes Registry of Saxony, Germany. Horm Res Paediatr, 2010. 74(4): p. 285-91.

[18] Skordis, N., et al., The incidence of type 1 diabetes mellitus in Greek-Cypriot children and adolescents in 1990-2000. Pediatr Diabetes, 2002. 3(4): p. 200-4.

[19] Toumba, M., et al., Rising incidence of type 1 diabetes mellitus in children and adolescents in Cyprus in 2000-2004. Pediatr Diabetes, 2007. 8(6): p. 374-6.

[20] Liese, A.D., et al., The burden of diabetes mellitus among US youth: prevalence estimates from the SEARCH for Diabetes in Youth Study. Pediatrics, 2006. 118(4): p. 1510-8.

[21] Thunander, M., et al., Incidence of type 1 and type 2 diabetes in adults and children in Kronoberg, Sweden. Diabetes Res Clin Pract, 2008. 82(2): p. 247-55.

[22] Felner, E.I., et al., Genetic interaction among three genomic regions creates distinct contributions to early- and late-onset type 1 diabetes mellitus. Pediatr Diabetes, 2005. 6(4): p. 213-20.

[23] Elamin, A., et al., Epidemiology of childhood type I diabetes in Sudan, 1987-1990. Diabetes Care, 1992. 15(11): p. 1556-9.

[24] Karvonen, M., J. Pitkaniemi, and J. Tuomilehto, The onset age of type 1 diabetes in Finnish children has become younger. The Finnish Childhood Diabetes Registry Group. Diabetes Care, 1999. 22(7): p. 1066-70.

[25] Schoenle, E.J., et al., Epidemiology of type I diabetes mellitus in Switzerland: steep rise in incidence in under 5 year old children in the past decade. Diabetologia, 2001. 44(3): p. 286-9.

[26] Haller, M.J., M.A. Atkinson, and D. Schatz, Type 1 diabetes mellitus: etiology, presentation, and management. Pediatr Clin North Am, 2005. 52(6): p. 1553-78.

[27] Turner, R., et al., UKPDS 25: autoantibodies to islet-cell cytoplasm and glutamic acid decarboxylase for prediction of insulin requirement in type 2 diabetes. UK Prospective Diabetes Study Group. Lancet, 1997. 350(9087): p. 1288-93.

[28] Gale, E.A. and K.M. Gillespie, Diabetes and gender. Diabetologia, 2001. 44(1): p. 3-15.

[29] Weets, I., et al., The incidence of type 1 diabetes in the age group 0-39 years has not increased in Antwerp (Belgium) between 1989 and 2000: evidence for earlier disease manifestation. Diabetes Care, 2002. 25(5): p. 840-6.

[30] Pundziute-Lycka, A., et al., The incidence of Type I diabetes has not increased but shifted to a younger age at diagnosis in the 0-34 years group in Sweden 1983-1998. Diabetologia, 2002. 45(6): p. 783-91.

[31] Quinn, M., et al., Characteristics at diagnosis of type 1 diabetes in children younger than 6 years. J Pediatr, 2006. 148(3): p. 366-71. 
[32] Adams, F., The seasonal variation in the onset of acute diabetes. The age and sex factors in 1000 diabetic patients. Arch Intern Med, 1926. 37: p.:861-864.

[33] Jun, H.S. and J.W. Yoon, A new look at viruses in type 1 diabetes. Diabetes Metab Res Rev, 2003. 19(1): p. 8-31.

[34] Moltchanova, E.V., et al., Seasonal variation of diagnosis of Type 1 diabetes mellitus in children worldwide. Diabet Med, 2009. 26(7): p. 673-8.

[35] Vaiserman, A.M., et al., Seasonality of birth in children and young adults (0-29 years) with type 1 diabetes in Ukraine. Diabetologia, 2007. 50(1): p. 32-5.

[36] Jongbloet, P.H., et al., Seasonality of birth in patients with childhood diabetes in The Netherlands. Diabetes Care, 1998. 21(1): p. 190-1.

[37] Samuelsson, U., C. Johansson, and J. Ludvigsson, Month of birth and risk of developing insulin dependent diabetes in south east Sweden. Arch Dis Child, 1999. 81(2): p. 143-6.

[38] Laron, Z., et al., Month of birth and subsequent development of type I diabetes (IDDM). J Pediatr Endocrinol Metab, 1999. 12(3): p. 397-402.

[39] McKinney, P.A., Seasonality of birth in patients with childhood Type I diabetes in 19 European regions. Diabetologia, 2001. 44 Suppl 3: p. B67-74.

[40] Mohr, S.B., et al., The association between ultraviolet B irradiance, vitamin $D$ status and incidence rates of type 1 diabetes in 51 regions worldwide. Diabetologia, 2008. 51(8): p. 1391-8.

[41] Todd, J.A., et al., Robust associations of four new chromosome regions from genome-wide analyses of type 1 diabetes. Nat Genet, 2007. 39(7): p. 857-64.

[42] Aly, T.A., et al., Extreme genetic risk for type 1A diabetes. Proc Natl Acad Sci U S A, 2006. 103(38): p. 14074-9.

[43] Thorsby, E. and K.S. Ronningen, Particular HLA-DQ molecules play a dominant role in determining susceptibility or resistance to type 1 (insulin-dependent) diabetes mellitus. Diabetologia, 1993. 36(5): p. 371-7.

[44] Stylianou, C.H., Apsiotou, N., Stavrou, S., Demetriades, M., Kyriakou, A., Costeas, P., Skordis, N., Detection of HLA-DR and DQB1 alleles, which predispose to diabetes mellitus type 1 in the Greek Cypriot population. Hormone Research, 2003. 60( (Suppl I)): p. 136.

[45] Atkinson, M.A. and N.K. Maclaren, The pathogenesis of insulin-dependent diabetes mellitus. N Engl J Med, 1994. 331(21): p. 1428-36.

[46] Redondo, M.J., et al., Genetic determination of islet cell autoimmunity in monozygotic twin, dizygotic twin, and non-twin siblings of patients with type 1 diabetes: prospective twin study. BMJ, 1999. 318(7185): p. 698-702.

[47] Gillespie, K.M., E.A. Gale, and P.J. Bingley, High familial risk and genetic susceptibility in early onset childhood diabetes. Diabetes, 2002. 51(1): p. 210-4.

[48] Gillespie, K.M., et al., The rising incidence of childhood type 1 diabetes and reduced contribution of high-risk HLA haplotypes. Lancet, 2004. 364(9446): p. 1699-700.

[49] Hermann, R., et al., Temporal changes in the frequencies of HLA genotypes in patients with Type 1 diabetes--indication of an increased environmental pressure? Diabetologia, 2003. 46(3): p. 420-5. 
[50] Gale, E.A., The rise of childhood type 1 diabetes in the 20th century. Diabetes, 2002. 51(12): p. 3353-61.

[51] Vehik, K., et al., Trends in high-risk HLA susceptibility genes among Colorado youth with type 1 diabetes. Diabetes Care, 2008. 31(7): p. 1392-6.

[52] Tsirogianni, A., E. Pipi, and K. Soufleros, Specificity of islet cell autoantibodies and coexistence with other organ specific autoantibodies in type 1 diabetes mellitus. Autoimmun Rev, 2009. 8(8): p. 687-91.

[53] Dahlquist, G.G., et al., Maternal enteroviral infection during pregnancy as a risk factor for childhood IDDM. A population-based case-control study. Diabetes, 1995. 44(4): p. 40813.

[54] Akerblom, H.K., et al., Dietary manipulation of beta cell autoimmunity in infants at increased risk of type 1 diabetes: a pilot study. Diabetologia, 2005. 48(5): p. 829-37.

[55] Longnecker, M.P. and J.L. Daniels, Environmental contaminants as etiologic factors for diabetes. Environ Health Perspect, 2001. 109 Suppl 6: p. 871-6.

[56] Hypponen, E., et al., Obesity, increased linear growth, and risk of type 1 diabetes in children. Diabetes Care, 2000. 23(12): p. 1755-60.

[57] McIntosh, E.D. and M.A. Menser, A fifty-year follow-up of congenital rubella. Lancet, 1992. 340(8816): p. 414-5.

[58] Rewers, M. and P. Zimmet, The rising tide of childhood type 1 diabetes--what is the elusive environmental trigger? Lancet, 2004. 364(9446): p. 1645-7.

[59] Salminen, K., et al., Enterovirus infections are associated with the induction of beta-cell autoimmunity in a prospective birth cohort study. J Med Virol, 2003. 69(1): p. 91-8.

[60] Betts, P., et al., Increasing body weight predicts the earlier onset of insulin-dependant diabetes in childhood: testing the 'accelerator hypothesis' (2). Diabet Med, 2005. 22(2): p. 144-51.

[61] Evertsen, J., R. Alemzadeh, and X. Wang, Increasing incidence of pediatric type 1 diabetes mellitus in Southeastern Wisconsin: relationship with body weight at diagnosis. PLoS One, 2009. 4(9): p. e6873.

[62] Virtanen, S.M. and M. Knip, Nutritional risk predictors of beta cell autoimmunity and type 1 diabetes at a young age. Am J Clin Nutr, 2003. 78(6): p. 1053-67.

[63] Norris, J.M., et al., Timing of initial cereal exposure in infancy and risk of islet autoimmunity. JAMA, 2003. 290(13): p. 1713-20.

[64] Ziegler, A.G., et al., Early infant feeding and risk of developing type 1 diabetes-associated autoantibodies. JAMA, 2003. 290(13): p. 1721-8.

[65] Vitamin D supplement in early childhood and risk for Type I (insulin-dependent) diabetes mellitus. The EURODIAB Substudy 2 Study Group. Diabetologia, 1999. 42(1): p. 51-4.

[66] Hypponen, E., et al., Intake of vitamin $D$ and risk of type 1 diabetes: a birth-cohort study. Lancet, 2001. 358(9292): p. 1500-3.

[67] Kleemann, R., et al., Impact of dietary fat on Th1/Th2 cytokine gene expression in the pancreas and gut of diabetes-prone BB rats. J Autoimmun, 1998. 11(1): p. 97-103.

[68] Krishna Mohan, I. and U.N. Das, Prevention of chemically induced diabetes mellitus in experimental animals by polyunsaturated fatty acids. Nutrition, 2001. 17(2): p. 12651. 
[69] Maahs, D.M., et al., Epidemiology of type 1 diabetes. Endocrinol Metab Clin North Am, 2010. 39(3): p. 481-97. 


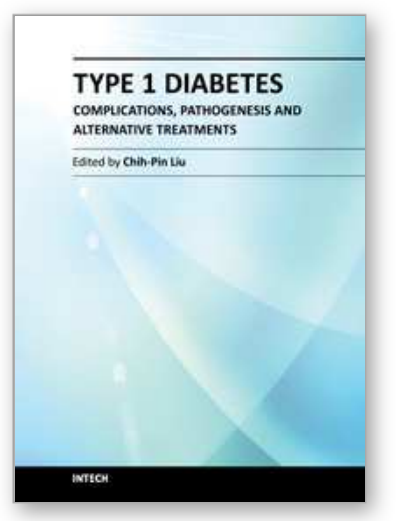

\author{
Type 1 Diabetes - Complications, Pathogenesis, and Alternative \\ Treatments \\ Edited by Prof. Chih-Pin Liu
}

ISBN 978-953-307-756-7

Hard cover, 470 pages

Publisher InTech

Published online 21, November, 2011

Published in print edition November, 2011

This book is intended as an overview of recent progress in type 1 diabetes research worldwide, with a focus on different research areas relevant to this disease. These include: diabetes mellitus and complications, psychological aspects of diabetes, perspectives of diabetes pathogenesis, identification and monitoring of diabetes mellitus, and alternative treatments for diabetes. In preparing this book, leading investigators from several countries in these five different categories were invited to contribute a chapter to this book. We have striven for a coherent presentation of concepts based on experiments and observation from the authors own research and from existing published reports. Therefore, the materials presented in this book are expected to be up to date in each research area. While there is no doubt that this book may have omitted some important findings in diabetes field, we hope the information included in this book will be useful for both basic science and clinical investigators. We also hope that diabetes patients and their family will benefit from reading the chapters in this book.

\title{
How to reference
}

In order to correctly reference this scholarly work, feel free to copy and paste the following:

Elisavet Efstathiou and Nicos Skordis (2011). Altering Trends in the Epidemiology of Type 1 Diabetes Mellitus in Children and Adolescents, Type 1 Diabetes - Complications, Pathogenesis, and Alternative Treatments, Prof. Chih-Pin Liu (Ed.), ISBN: 978-953-307-756-7, InTech, Available from:

http://www.intechopen.com/books/type-1-diabetes-complications-pathogenesis-and-alternativetreatments/altering-trends-in-the-epidemiology-of-type-1-diabetes-mellitus-in-children-and-adolescents

\section{INTECH}

open science | open minds

\section{InTech Europe}

University Campus STeP Ri

Slavka Krautzeka 83/A

51000 Rijeka, Croatia

Phone: +385 (51) 770447

Fax: +385 (51) 686166

www.intechopen.com

\section{InTech China}

Unit 405, Office Block, Hotel Equatorial Shanghai

No.65, Yan An Road (West), Shanghai, 200040, China 中国上海市延安西路65号上海国际贵都大饭店办公楼405单元

Phone: +86-21-62489820

Fax: +86-21-62489821 
(C) 2011 The Author(s). Licensee IntechOpen. This is an open access article distributed under the terms of the Creative Commons Attribution 3.0 License, which permits unrestricted use, distribution, and reproduction in any medium, provided the original work is properly cited. 